Check for updates

London

Cite this as: BMJ 2021;374:n2299 http://dx.doi.org/10.1136/bmj.n2299 Published: 17 September 2021

\section{New public health body will be responsible for "levelling up" health, health secretary says}

\author{
Ingrid Torjesen
}

The organisation set to take over Public Health England's leadership role in health promotion and illness prevention from 1 October will be called the Office for Health Improvement and Disparities to underline the government's commitment to "level up" health, the health and social care secretary Sajid Javid has announced. It had been expected that it would be called the Office for Health Promotion.

Javid, who took on the health brief on 26 June, said, "When I came into this job, my thoughts turned to what this office-with that weighty responsibility of shifting the dial on how we improve health and prevent disease-would need to focus on to achieve its mission. It's not just a change of name but a statement of intent-a driving mission to 'level up' health and ensure everyone has the chance to live happy and healthy lives."

The government wanted to use the post-covid recovery to "build back fairer" to create a more level playing field in society, he said. "Our recovery from covid-19 can't be limited to supporting the economy. After all, we can only level up economically if we level up in terms of health too."

He said the pandemic had left the NHS facing two backlogs: massive waiting lists, with more than 5.5 million waiting for elective treatments; and a social backlog in mental health and public health which is "much harder to quantify" and "less evenly spread."

The pandemic had highlighted starkly how lifestyle and underlying health determine resilience to new risks and diseases and "like a receding tide" had revealed the underlying health of our nation, he added. "It hit much harder those people, places, and communities whose underlying health was poorer. People who smoked, who were overweight, or who struggled with chronic conditions."

Admission rates to hospital for covid-19 were 2.9 times higher in the most deprived areas of England compared with the least deprived, and the mortality rate was 2.4 times higher. Minority ethnic groups were more likely to be admitted to critical care for, and die from, covid-19 than white British people.

While for some people covid-19 was "a wake up call to get fit and get healthy," for others it went the other way and, as a result, "healthy people were getting healthier, while unhealthy people were becoming unhealthier still," Javid said. "We need to reverse that trend-and we need to do it fast."

Cancers and cardiovascular disease account for over $60 \%$ of years of life lost to premature death, and risk of premature death from these causes varies greatly depending on where people live. More needed to be done to understand and tackle these inequalities, he said. "We need to make it easier for people to access screening services and diagnostics. And we need to make sure that everyone can get the support they need from primary care-which is often the first to spot the early signs of a problem.”

The Office for Health Improvement and Disparities will look at how better to prevent poor mental and physical health through tackling tobacco use, obesity, poor diet, and the harmful use of alcohol and drugs, Javid said. It will also work with partners-including the NHS, industry, life sciences, and academia-to tackle health inequalities and variable access to health services, and with partners across government and beyond to act on wider factors, such as housing, education, environment, and employment, that contribute to health outcomes.

Jennifer Dixon, chief executive of the Health Foundation, said, "We now need action to follow these warm and welcome words. The reality is that public health funding has been cut by over £1bn ( $€ 1.2 \mathrm{bn} ; \$ 1.4 \mathrm{bn}$ ) in the past 10 years and further cuts have been made to services that are fundamental to people's health, like education and housing. The level of basic income also impacts health and the end to the universal credit uplift of £2o per week on 6 October will impact the poorest and sickest in England. Government investment is needed now to reverse the trends."

She added, "As the health secretary has identified, government action on the wider factors that impact health-including education, housing, and welfare-will be essential to this mission." 